\title{
USING AGENT-BASED MODELING AND HUMAN-IN-THE-LOOP SIMULATION TO ANALYZE ARMY ACQUISITION PROGRAMS
}

\author{
MAJ Patrick M. Downes \\ Department of Systems Engineering \\ United States Military Academy \\ West Point, NY 10996, U.S.A
}

\author{
LTC Michael J. Kwinn Jr. \\ Department of Systems Engineering \\ United States Military Academy \\ West Point, NY 10996, U.S.A
}

\author{
Donald E. Brown \\ Department of Systems and \\ Information Engineering \\ University of Virginia \\ Charlottesville, VA 22904, U.S.A
}

\begin{abstract}
The purpose of this research is to demonstrate the usefulness of integrating human-in-the-loop simulations and agent based modeling. The integration of a human-in-theloop simulation with an agent based model can model information technology systems. This integration allows analysts to exploit the strengths and advantages of each of these two model types. The integration and power of these models together diminishes each of the models own inherent disadvantages and limitations. This unique partnership between two distinct model types can tell analysts how well information technology systems provide users with information, data, and intelligence. This valuable insight about information systems' performance can be an indispensable aide to those interested in comparing, rating, and acquiring alternative information systems.
\end{abstract}

\section{INTRODUCTION}

This paper will describe how the integration of a humanin-the-loop simulation and an agent based model was used to simulate the performance of an information system designed for the United States Army. The two simulations provide insight into how well the information system performs and are valuable to those managing the acquisition, design, and production of information systems. We will discuss the advantages of integrating these modeling techniques and show how this partnership can contribute to the analysis of information systems. The integration of these two unique simulation types can be used to model the performance of information systems in other arenas as well.
The United States Army Land Warrior Project is an attempt to bring information technology to the infantry squad level and consider each individual soldier as a weapon system. The Land Warrior System has five primary functions:

- Lethality

- Survivability

- Mobility

- Reliable, Trustworthy Systems

- Situational Awareness.

In order to measure the performance of the Land Warrior System, it is important to measure a squad's performance in each of these five functional areas. It is a rather simple matter to measure a squad's ability to survive on the battlefield, a squad's ability to destroy enemy forces and a squad's ability to maneuver on the battlefield. It is not trivial to measure an individual's situational awareness or a squad's situational awareness. Our integration allowed us to assess how well the Land Warrior equipment provides users with information and how well users were able to use this information.

Increased situational awareness focuses on the soldier's ability to perceive his environment and how the use of information can improve his lethality, survivability, and ability to accomplish his mission. For a soldier, situational awareness means understanding how friendly forces, enemy forces, and terrain interact and using this understanding to make decisions concerning future courses of action. Simply stated, situational awareness is "knowing what is going on.” (Infantry Forces Research Unit 2001) 
In this paper, we will describe a multi agent based simulation and a human-in-the-loop simulation. We will then describe the components of the Land Warrior System and how we integrated our multi agent model and humanin-the-loop simulation. This integration will allow us to predict how well the Land Warrior System provides users information. This integration will also allow us to explore the relationship between increased situational awareness and other squad performance measures.

\section{MULTI AGENT BASED MODEL}

The simulation of an information system's performance must represent both the information system itself and the "agents" or users of an information system. The simulation of agents using information systems is difficult because there are many complex relationships and interactions that are difficult to capture in a simulation. We can consider agents to be "a wide spectrum of computational entities that can sense their local task conditions and make decisions how to react to sensed conditions by performing certain behaviors in task environments". (Liu, 2001) To better understand complex systems, we need to be able to model the interaction of agents and how they react to each other.

\subsection{MANA Simulation}

One such multi agent based model that is specifically designed to model combat and how soldiers interact is the multi agent based combat model, Map Aware Non-uniform Automata (MANA). Specifically, this simulation provides an excellent venue to investigate the relationship between increased situational awareness and lethality and survivability. MANA has the ability to model information systems that provide agents with varying amounts of information and situational awareness.

MANA has many familiar combat model properties. Its two greatest benefits are its semi-automated agents and its ability to model situational awareness. Each individual soldier is represented as an agent in MANA with distinct personality properties. Some of the key personality properties are the agent's Firepower, essentially the agent's probability of hit, and its Stealth, an agent's ability to hide from the enemy and be covered from an enemy's direct fire weapon systems. Agents are grouped together into squads and share joint properties such as Sensor Range and Firing Range. These shared properties dictate how far apart agents can be and still communicate and the range of their direct fire weapon systems. (Lauren 2001)

\subsection{Threat Influence Range}

MANA models situational awareness by giving each a squad a Threat Influence Range. Ideally, if an agent in a squad made contact with enemy forces, that agent would be able to share information with all of the other agents in its squad. Realistically, this ability to share such pertinent information is hindered by the fog of war, reliability of radio communications, how far dispersed maneuver formations are, and the soldiers' ability to accurately transmit information and intelligence.

Each squad is given a Threat Influence Range value from 1 to 255. This number represents the area of a squad information box. Any agent that is maneuvering inside of a friendly agent's Threat Influence Range is privy to all information and intelligence the squad has. For example, if the lead member of a squad makes contact with a two man enemy sentry outpost, if the squad has a large Threat Influence Range, than all of the member of the squad will operate with a common picture of the battlefield. If a squad's Threat Influence Range is relatively low, then some agents in the squad will be outside of the Threat Influence range and will not be operating with a common picture of the battlefield. Generally, agents and squads will more situational awareness have a larger Threat Influence Range than agents and squads that are not as situationally aware. (Lauren 2001)

\section{HUMAN-IN-THE-LOOP SIMUALTION}

MANA allows analysts to model varying levels of effectiveness for information systems. However, how can we be certain that one information system provides more or less information than another? A human-in-the-loop simulation can provide analysts a medium to determine whether or not two information systems provide varying amounts of information and situational awareness to users. This relative worth of alternative information systems can be an input parameter to the agent model.

\subsection{Dismounted Simulation Acquisition System (DSAS)}

An ideal method to observe the performance of an information system would be to provide real subjects with the actual information system of interest. Analysts could design a series of experiments that would test how well the subjects use the system. For example to measure the performance of the Land Warrior System, Land Warrior equipped soldiers could conduct a series of military training exercises. However, such studies are costly and time consuming. Therefore, a human-in-the-loop simulation can be used to model the performance of Land Warrior equipped soldiers in a less expensive and more efficient manner.

One example of a human-in-the-loop simulation is the Dismounted Simulation Acquisition System (DSAS) developed by videogame manufacturer, NovaLogic Systems. DSAS was the resulting product of a relationship between NovaLogic Systems and the Army's Training and Doctrine Command (TRADOC) Analysis Center (TRAC) Monterey. 
NovaLogic's popular Delta Force: Land Warrior game was modified to include the key components of the Land Warrior System (Fudge 2000). DSAS employs a computer network that allows multiple subjects to participate in the same scenario. Multiple participants can see each other and interact with each other on the simulated battlefield. Participants see each other as life-like icons in the virtual reality simulation. Each participant has an individual computer and controls his virtual soldier's ability to move and shoot through the computer keyboard. (Pleban 1998)

DSAS models the Land Warrior System equipment. A subject in this simulation can be equipped with this information system and put through a series of experiments. A subject without the Land Warrior System can also be put through the same series of experiments. The performance of the two different subjects can be compared to determine whether the Land Warrior System provides valuable information.

\section{INTEGRATING AGENT BASED MODELS AND HUMAN-IN-THE-LOOP SIMULATIONS}

We will now describe how we integrated these two types of simulation and modeling techniques to determine how well a specific information system performs in a complex operating environment. We will describe further the Army's Land Warrior Project. We will explore some of the metrics that are of interest when evaluating alternative combat information systems and weapon systems. We will then outline our analytical approach to integrating the two simulations.

\subsection{Land Warrior System}

The Army's Land Warrior Project is an effort to enhance the infantry rifle squad's lethality and survivability through increased situational awareness. The Land Warrior system is intended to enhance a soldier's ability to communicate with his fellow soldiers on the battlefield. This sharing of information in the form of digital communication, computer generated graphics, and video imagery, when disseminated throughout a unit by utilizing improved communication structures, should improve a unit's ability to close with and destroy the enemy.

The Land Warrior System has several subsystems. The first is the soldier's individual weapon, the M-16/M4 carbine. The weapon is enhanced with several electrical optical components. The soldier is equipped with a Thermal Weapon Sight, which improves his ability to engage targets in limited visibility. A video camera attachment gives the soldier the ability to send visual images to higher headquarters and other squad members. A laser range finder and digital compass serve as both a navigational tool and to help the soldier to call for indirect fire.

The Land Warrior soldier is also equipped with an Integrated Helmet Assembly Subsystem. This subsystem is composed of an improved ballistic helmet, as well as the soldier's helmet mounted computer and sensor display. Soldiers use this display to view computer-generated maps, operational graphics, friendly troop locations, and imagery from the Thermal Weapon Sight. The display is the component that will allow a soldier to fire his weapon without exposing himself to enemy fire. (Federation of American Scientists 1999)

\subsection{Measuring Land Warrior Performance}

There are many effective measures to determine lethality or survivability of a combat system. The number of enemy forces destroyed, percentage of forces remaining after an engagement, and loss exchange ratios are all popular evaluation measures. It is not as simple to measure a soldier's situational awareness nor how much a combat system improves a soldier's situational awareness.

\subsubsection{Measuring Situational Awareness}

Objective measures of situational awareness attempt to measure a subject's knowledge about his or her environment and compare his or her perception to the actual truth. Techniques of this nature are called comparisons to the Ideal Observer (Green 1998). The ideal observer has perfect information about a particular environment and understanding of his or her interaction with it. By comparing a subject's knowledge of the environment to the ideal observer's, researchers can measure the amount of error in the subject's perception. For example, a subject undergoing an infantry squad operation simulation can be surveyed about what his unit's location is. Analysts are then able to compare this answer to the exact location of the unit and measure the difference in concrete numbers.

\subsection{Measuring Situational Awareness in a Human-in-the-Loop Simulation}

Our hypothesis was that the Land Warrior's increased communications capability would allow the squad and the individual soldiers to move with greater coordination and speed. When combined with the soldier's improved weaponry, the effects would be a more lethal, agile, more situationally aware, and ultimately a more survivable dismounted unit. Central to the further development of the system was providing analytical proof that the Land Warrior System provided the infantry soldier significant improvements in situational awareness and, ultimately, greater lethality and survivability than with his current equipment. Once we had confirmed our hypothesis, we could use more complex models to determine how great the effect of increased situational awareness was on the other performance measures. Outputs from our human-in-the-loop simulation would serve as critical inputs into our agent model. 
We realized one way to measure a soldier's situational awareness was to subject an infantry soldier to a series of questions during an exercise. To address this issue, we experimented using a DSAS simulation. This experiment would measure the situational awareness of both Land Warrior equipped infantry soldiers and non-Land Warrior equipped infantry soldiers. In order to conduct the experiments with an experienced test group and to execute multiple replications, we employed West Point cadets participating in their Military Science courses.

\subsubsection{The Analysis Group}

First year cadets at the United States Military Academy (USMA) are first introduced to tactics in a classroom environment in their Military Science (MS) 102 course. In MS 102 , cadets investigate fundamental war fighting principles. These include Ground Maneuver Theory, Elements of Combat Power, Principles of War, and the factors of Mission, Enemy, Time, Terrain, Troops Available, and Civilian Considerations (METT-TC). Instructors use accounts of warfare from text and film to illustrate these fundamentals, and augment these classroom presentations with interactive simulations.

\subsubsection{The Simulation}

The cadet simulation exercises used the Dismounted Simulation Acquisition System (DSAS). In this virtual combat environment, cadets acted as members of an infantry squad and conducted a deliberate attack mission. For this simulation exercise, the Blue Forces and Red Forces were arrayed as depicted in Table 1.

Table 1: Force Allocations

\begin{tabular}{|l|c|c|l|}
\hline $\begin{array}{l}\text { Duty } \\
\text { Position }\end{array}$ & $\begin{array}{l}\text { Blue } \\
\text { Forces }\end{array}$ & $\begin{array}{l}\text { Red } \\
\text { Forces }\end{array}$ & $\begin{array}{l}\text { Weapon } \\
\text { System }\end{array}$ \\
\hline $\begin{array}{l}\text { Squad } \\
\text { Leader }\end{array}$ & 1 & 1 & M16 Rifle \\
\hline $\begin{array}{l}\text { Team } \\
\text { Leader }\end{array}$ & 2 & 1 & M16 Rifle \\
\hline Grenadier & 2 & 1 & $\begin{array}{l}\text { M203 Grenade } \\
\text { Launcher }\end{array}$ \\
\hline $\begin{array}{l}\text { Automatic } \\
\text { Rifleman }\end{array}$ & 2 & 1 & $\begin{array}{l}\text { M249 Squad } \\
\text { Automatic } \\
\text { Rifleman }\end{array}$ \\
\hline Rifleman & 2 & 1 & M16 Rifle \\
\hline
\end{tabular}

In this exercise, the Blue Force squad is given the mission to attack the defending Red Force squad. The Blue Force has to maneuver approximately 1000 meters to be in a position to attack the Red Forces. The Red Forces are defending a communications site that includes a radio tower and multiple bunkers as prepared defensive positions. The simulation does not simulate indirect fire (artillery) nor does it allow either side to request reinforcements.
Though the soldiers can see each other on the virtual battlefield, they are not capable of communicating with each other. To simulate squad communication systems, the participants sat facing a row of computers with the squad leader in the center and one fire team to his right, the other to his left. This allowed the squad leader to communicate with his two team leaders in order to command and control his soldiers.

The DSAS simulation also has the ability to simulate the Land Warrior Equipment. This feature allows the participant to view a topographical military map on a simulated heads up display. This map contains operational graphics, but more importantly, it also tracks the location of friendly forces. This heads up display becomes a window on the soldier's computer monitor and is viewed along with the simulation. As the unit maneuvers through the battle space, the map continues to update itself allowing the force to know where all friendly elements are. For example, if a squad leader sends one of his fire teams to establish a support by fire position, the squad leader can visually monitor their progress by watching the support by fire team's icon on the heads up display.

Before executing the simulation, cadets received detailed instruction on how to use the program, including use of the Land Warrior enhanced visual map. The cadets also received detailed mission instructions about their scenario. Though the cadets are not seasoned veterans or masters of tactics, they have an understanding of the essential principles of squad warfare. Additionally, the instructors were instrumental in helping the cadets' plan and rehearse their operations orders for the simulation.

\subsubsection{Analytic Approach}

During the simulations, we administered a survey to the Blue Force squad leader and team leaders, whether they were equipped with the Land Warrior equipment or not. The goal of the survey was to measure the soldiers' situational awareness. The survey's focus was on asking questions about the Blue Forces, the Red Forces, and the terrain. Good situational awareness is considered an understanding of how friendly forces, enemy forces, and the terrain interact. If a leader has knowledge of these three areas and their interaction, then he is exhibiting good situational awareness.

For example, at the start of the simulation, the squad leader's first mission was to conduct a leader's reconnaissance. Simultaneously, they would answer survey questions like "What is the direction and distance to your objective"? The soldiers equipped with Land Warrior were able to use their heads up display and quickly answer the questions. The soldiers with out Land Warrior had to use their hand held maps, compasses, and protractors to answer the question.

The soldier's answers were compared to the ground truth data collected from the start of the simulation by the 
administrators. This comparison allowed us to quantify their perception of their surroundings; in essence measuring their situational awareness. A comparison of the subject's answer to the Green's Ideal Observer, who is all knowing, is done in the following manner:

\section{Subject's Distance from Ideal Observer $=$ |Truth- Subject's Answer|}

The smaller this number, then the closer the subject is to the Ideal Observer, and the more aware the subject is of his surroundings. We call this difference the subject's Ideal Observer Score. For example, if a soldier responded to the question about the distance to his objective by saying 750 meters and the actual distance was 725 meters, that soldier would have an Ideal Observer Score of 25. If a second soldier responded to the same question by saying 800 meters, this second soldier would have an Ideal Observer Score of 75. Naturally, we would say the first soldier has better situational awareness because his Ideal Observer Score is lower. In this example, the Ideal Observer Score is in terms of meters.

\subsubsection{The Results}

We were able to conduct a total of 29 experiments of the simulation exercise. A new set of cadets participated in each experiment or iteration. During each of the 29 different iterations, we assessed the situational awareness of each squad's squad leader and its two team leaders was assessed using a survey of relevant questions designed to quantify the soldier's understanding of his or her environment and the Ideal Observer Score method. As an additional matter of interest, we also collected statistics that would help us measure the lethality and survivability of the Blue Forces. Specifically, we collected data about the number of Blue and Red Force casualties.

The situational awareness measures clearly showed that the Land Warrior equipped soldiers had a clearer understanding of the interaction of friendly forces, enemy forces, and the terrain than the soldiers who were not Land Warrior equipped. The Land Warrior soldiers had much better Ideal Observer scores, especially on the questions that asked the soldiers to provide an eight digit grid location. The Land Warrior heads up display helped these soldiers be far more accurate than the non Land Warrior equipped subjects. Overall, the Land Warrior equipped soldiers had an average Subject's Distance from Ideal Observer or Ideal Observer score of 33.8 and the non Land Warrior equipped soldiers had an Ideal Observer score of 194.0. Clearly, the indicators show that soldiers with Land Warrior equipment were much better equipped and prepared to answer the situational awareness surveys than the non Land Warrior equipped soldiers.

There was a statistically significant difference in the amount of situational awareness exhibited by the Land
Warrior equipped soldiers and the non Land Warrior equipped soldiers. However, we could not conclude that the increased situational awareness of the Land Warriorequipped soldiers led to increased lethality and survivability. But our experimental data that clearly supported our initial supposition that Land Warrior would provide infantry soldiers' increased situational awareness, as measured by their Ideal Observer scores would serve as an important input to our second simulation.

\subsection{MANA Simulation}

We set out to build a model of the human-in-the-loop simulation run with DSAS in MANA. Both sides were similarly task organized and given similar missions. The Blue Force personality weights were programmed to ensure they would remain on the offensive and attempt to destroy the Red Forces, who were programmed to establish a defensive battle position. The Blue Forces were programmed to react to enemy contact by getting in the prone and subsequently moving more cautiously and deliberately.

\subsubsection{Scenarios}

The first scenario was designed to answer the question: Does increased situational awareness improve the overall performance of the soldier in MANA? By taking advantage of MANA's Threat Influence Range, the situational awareness parameter, we designed an experiment where Blue and Red Forces had varying amounts of situational awareness. We used five different levels for Blue's Threat Influence Range. The second scenario varied Blue's Threat Influence Range, Blue's Stealth, Blue's Firepower, and Blue's Sensor Range parameters. Each of these factors had two levels.

After analyzing the results of the first two scenarios, there was not an apparent relationship between increased situational awareness and improved squad lethality and survivability. One of the explanations for a failure of a relationship to appear was the lack of integration of other combat multipliers in our experiment. Our experiments were rather simple and symmetric. We designed additional scenarios that would be more complex and realistic by integrating additional battlefield operating systems.

Our remaining scenarios were designed to simulate the Blue Forces fighting a combined arms battle. The Army defines combined arms operations as those operations that have more than one battlefield operating system working in conjunction with each other towards mission accomplishment. (Department of the Army 2001) MANA does not have the capability to simulate indirect fire, such as artillery or mortar fire; however a direct fire system can be designed within MANA that will behave like an indirect fire weapon system. This indirect fire weapon system is designed to support the Blue Forces' maneuver plan.

The third scenario varied only the Blue Force's Threat Influence Range. In the fourth scenario, just as in the sec- 
ond, we varied the Blue Force's Threat Influence Range, Stealth, Firepower, and Sensor Range. We varied one other additional factor here. The Blue Force agents were divided into three separate squads and we varied whether or not the three Blue Force squads could or could not share information. For example, even if the Blue Force Threat Influence Range was high, if we did not allow the three squads to communicate, they were incapable of sharing this good situational awareness.

\section{RESULTS}

The results from our first two scenarios did not lend themselves to any significant conclusions. In the first scenario, we saw a slight positive relationship between improved situational awareness and Blue survivability, but there was no such relationship between improved situational awareness and Blue lethality.

Our second scenario provided some significant results, but increased situational awareness was not one of our significant factors. The two greatest and significant factors on both the number of Blue Casualties (Blue Survivability) and Red Casualties (Blue Lethality) were Blue Stealth and Blue Firepower. Although this result does not support our original hypothesis, it is consistent with other military lessons reinforced by an endless number of historical examples.

In our third scenario, one of our combined arms scenarios, we finally discovered a strong relationship between improved situational awareness and Blue Force Lethality and Survivability. In Figure 1, we see the dramatic decrease in the number of Blue Casualties and increase in the number of Red Casualties when Blue Situational Awareness is increased.

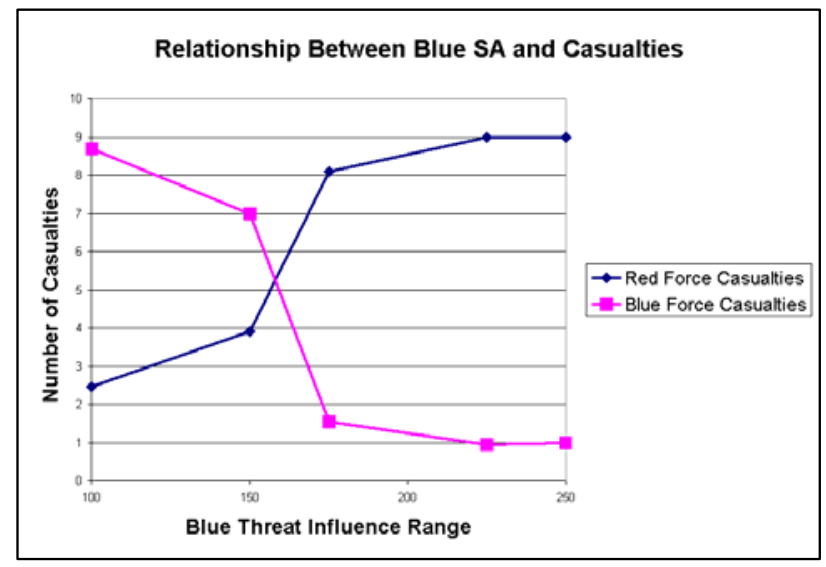

Figure 1: Relationship between Blue Situational Awareness and Blue and Red Force Casualties

In this third scenario, the Blue Forces' improved situational awareness allowed them to take advantage of the additional combat multiplier, the simulated indirect fire weapon systems. As the Blue Force's situational aware- ness improved, their forces appeared to become more survivable and more lethal. The fourth scenario also indicated a positive relationship between improved Blue situational awareness and Blue lethality and survivability.

The Blue Force was only able to take advantage of its superior situational awareness and information networks when the additional combat multiplier, the simulated indirect fire asset, was introduced to the simulation. In Experiments One and Two, the Blue Forces had the same enhanced situational awareness but they did have the ability to share this information. In essence, in Experiments One and Two, the Blue Forces had critical battlefield information, the exact location of the Red Forces, but there was no additional combat multiplier at their disposal to commit to act upon this additional information. This additional information could not be shared with an element that could help the Blue Force. In Experiments Three and Four, the Blue Forces were able to provide this information to the simulated artillery piece and it made a positive impact on the battle.

\section{CONCLUSIONS}

Our research led us to three primary conclusions. The Land Warrior system clearly provides soldiers with greater situational awareness and that it is a beneficial information system for soldiers. This assessment is based on the objective measures taken during the DSAS simulation. This assessment is not based on assumptions about how improved sensors and improved communication structures could lead to improved situational awareness. Rather, it is based on objective analysis. The validation that the Land Warrior soldier has improved situational awareness helps the Army confirm that they are meeting one of the primary functions of the Land Warrior system, which is to increase situational awareness.

Secondly, increased situational awareness appears to contribute to increased lethality and survivability, with a very important caveat. This improvement can only be seen on a battlefield where forces with improved situational awareness are fighting as part of a combined arms force. Military leaders must avoid the temptation to assume that if a maneuver force has increased situational awareness, then there is no need to allocate valuable combat support assets to aid the maneuver force. The force with improved situational awareness can only take advantage of their enhanced abilities to communicate and share a common vision of the battlefield if the are given additional combat multipliers such as artillery or attack helicopters. Further research into the nature of the relationships between improved situational awareness and the soldiers' improved lethality and survivability would be of great interest to military commanders.

Lastly, this description of how a human-in-the-loop simulation and a multi-agent based simulation can be integrated to answer specific problems facing today's Army may lead to similar partnerships. Without this integration, 
we would not have been able to make the two previous conclusions. These two conclusions imply that the Land Warrior System is a superior information system to the equipment present day Infantry soldiers are outfitted with. This assessment of the Land Warrior Systems' worth as an information system is vital to the acquisition process. Using a methodology similar to the one outlined here, analysts from a wide variety of fields can measure the performance of other information systems. This methodology not only focuses on whether or not the information system provides improved information, but what is the effect on other critical performance measures.

\section{REFERENCES}

Department of the Army. 2001. Field Manual 3-0: Operations. Washington, D.C.

Fudge, J. 2000. Delta Force II Chosen by U.S. Army. Available online via $<$ http: / / www. cdmag. com/ articles/027/007/d2_army.html> [accessed April 15, 2004].

Federation of American Scientists. 1999. Land Warrior. Available online via $<$ http : / / www . fas.org/ man/dod-101/sys/land/l andwarrior.htm > [accessed April 15, 2004].

Green, M. J. Odom, J. Yates. 1998. Measuring Situation Awareness with the 'Ideal Observer'. Available online via $<$ http: / / www . ergogero. com/ sitaw/sitaware.html> [accessed April 15, 2004].

Infantry Forces Research Unit. 2001. Measures of Platoon Leader Situation Awareness in Virtual Decision Making Exercises. Available online via <http: //www . benning . army.mil arifb/Reports/2001> [accessed April 15, 2002].

Lauren, Michael, R. Stephen. 2001. Map Aware NonUniform Automata Users Manual. Australia. Defence Science and Technology Organisation.

Liu, Jiming. 2001. Autonomous Agents and Mulit-Agent Systems. New Jersey. World Scientific.

Pleban, Robert J. 1998. Functional capabilities of four virtual individual combatant (VIC) simulator technologies: an independent assessment. Alexandria, Virginia. U.S. Army Research Institute for the Behavioral and Social Sciences.

\section{AUTHOR BIOGRAPHIES}

PATRICK M. DOWNES is an Assistant Professor in the Department of Systems Engineering at the United States Military Academy. He graduated with a B.S. in Systems Engineering from the United States Military Academy at West Point in 1993 and was commissioned as an Infantry Officer. He has served with the 25th Infantry Division at Schofield Barracks, Hawaii and the 1st Armored Division,
Fort Riley, Kansas. MAJ Downes earned a M.S. in Systems Engineering from University of Virginia in 2000. His email address is <patrick.downes@usma.edu>.

MICHAEL J. KWINN, JR., Ph. D. is an Associate Professor and the Director of the Operations Research Center of Excellence at USMA. His military assignments include Fort Bliss, TX, Germany, Colorado, and South Korea. He earned a BS from USMA in 1984, a MS in Systems and Industrial Engineering from the University of Arizona in 1994 and a Ph.D. from the University of Texas Red McCombs School of Business in 2000. His research interests include optimization and simulation as well as combat system requirements development and assessment methodology development. He is a member of the Board of Directors for the Military Operations Research Society. His email address is <michael.kwinn@usma.edu> .

DONALD E. BROWN, Ph. D. is Professor and Chair of the Department of Systems and Information Engineering at the University of Virginia. He received a Ph.D. degree in Industrial and Operations Engineering from the University of Michigan, a M.S. and M.Eng. degrees in Operations Research and Industrial Engineering, respectively from the University of California, Berkeley, and a B.S. degree from the U.S. Military Academy, West Point. His research is in statistical learning, data mining, data fusion, and simulation-optimization. Dr. Brown's email address is<brown@virginia.edu> . 